\title{
Targeted therapeutic mild hypercapnia after cardiac arrest: a part of the bundle of care for mitigating secondary injury after cardiac arrest
}

\author{
Romain Jouffroy ${ }^{*}$ and Benoît Vivien
}

In the July 31 issue of Critical Care, Eastwood and colleagues [1] discussed the discordant results of the potential therapeutic role of mild hypercapnia in the early post-resuscitation period observed by Sekhon and colleagues [2].

These two previous studies $[1,2]$ underlined the importance of preventing secondary cerebral injury after cardiac arrest and the role of arterial carbon dioxide on cerebral blood flow modulation in this. As described by Adrie and colleagues [3], cardiac arrest and sepsis have physiopathological similarities, including similar therapeutic interventions. For the management of septic shock, one major prognostic factor is the early initiation of appropriate treatments [4]. As underlined by Sekhon and colleagues [2], the negative results from randomized control trials of single physiological interventions (targeted temperature management and transfusion) aiming to avoid secondary injury after cardiac arrest are probably due to pathophysiological heterogeneity. Beyond this heterogeneity, we believe that, like in sepsis management, at a population scale, the benefit of a bundle of care including targeted therapeutic mild hypercapnia will be greater than a single intervention as described by Scheer and colleagues [5]. If a bundle of care to prevent secondary cerebral injury after cardiac arrest is useful to help physicians in the early stage management of these patients, personalized physiologic resuscitation targets following this stage would probably be more beneficial after intensive care unit admission. In the intensive care unit, further investigation can be performed to personalize resuscitation but will be in vain if the early stage is not managed properly.

\author{
Acknowledgements \\ None. \\ Funding \\ None.
}

Availability of data and materials Not applicable.

\begin{abstract}
Authors' contributions
$\mathrm{RJ}$ and $\mathrm{BV}$ wrote and revised the manuscript. Both authors read and approved the final manuscript.
\end{abstract}

Ethics approval and consent to participate Not applicable.

Consent for publication

$\mathrm{RJ}$ and $\mathrm{BV}$ consent for publication.

Competing interests

The authors declare that they have no competing interests.

\section{Publisher's Note}

Springer Nature remains neutral with regard to jurisdictional claims in published maps and institutional affiliations.

Published online: 07 September 2017

\section{References}

1. Eastwood GM, Nichol A, Wise MP. Targeted therapeutic mild hypercapnia after cardiac arrest. Crit Care. 2017;21(1):196

2. Sekhon MS, Ainslie PN, Griesdale DE. Clinical pathophysiology of hypoxic ischemic brain injury after cardiac arrest: a "two-hit" model. Crit Care. 2017; 21(1):90.

3. Adrie C, Laurent I, Monchi M, et al. Postresuscitation disease after cardiac arrest: a sepsis-like syndrome? Curr Opin Crit Care. 2004;10(3):208-12.

4. Leisman DE, Doerfler ME, Ward MF et al. Survival benefit and cost savings from compliance with a simplified 3-hour sepsis bundle in a series of prospective, multisite, observational cohorts. Crit Care Med. 2017:45(3):395-406.

5. Scheer CS, Fuchs C, Kuhn SO, et al. Quality improvement initiative for severe sepsis and septic shock reduces 90-day mortality: a 7.5-year observational study. Crit Care Med. 2017;45(2):241-252.

\footnotetext{
*Correspondence: romain.jouffroy@aphp.fr

SAMU de Paris, Service d'Anesthésie Réanimation, Hôpital Necker - Enfants

Malades, Assistance Publique - Hôpitaux de Paris, and Université Paris

Descartes - Paris 5, Paris, France
}

(c) The Author(s). 2017 Open Access This article is distributed under the terms of the Creative Commons Attribution 4.0 International License (http://creativecommons.org/licenses/by/4.0/, which permits unrestricted use, distribution, and reproduction in any medium, provided you give appropriate credit to the original author(s) and the source, provide a link to the Creative Commons license, and indicate if changes were made. The Creative Commons Public Domain Dedication waiver (http://creativecommons.org/publicdomain/zero/1.0/) applies to the data made available in this article, unless otherwise stated. 